\title{
Efficacy of eribulin in breast cancer: a short report on the emerging new data
}

\author{
This article was published in the following Dove Press journal: \\ OncoTargets and Therapy \\ 13 February 2017 \\ Number of times this article has been viewed
}

\section{Gelareh Eslamian \\ Caroline Wilson \\ Robin J Young}

Academic Unit of Clinical Oncology, Weston Park Hospital, Sheffield, UK
Correspondence: Robin J Young Academic Unit of Clinical Oncology, Weston Park Hospital, Sheffield SIO 2SJ, UK

Tel +44 II4 2265000

Email r.j.young@sheffield.ac.uk

\begin{abstract}
Eribulin is a novel microtubule-targeting agent that is approved for the treatment of patients with locally advanced or metastatic breast cancer who have previously received treatment with an anthracycline and a taxane in either the adjuvant or metastatic setting. Eribulin induces mitotic catastrophe leading to cell death but has other important antitumor effects, including reversal of epithelial-mesenchymal transition and remodeling of the tumor vasculature. Eribulin was licensed for the treatment of advanced breast cancer based on results from two large randomized Phase III clinical trials. Current clinical trials of eribulin for breast cancer are evaluating response to treatment earlier in the patient pathway and in combination with other therapeutic agents. This review provides a short overview of emerging new data on the mode of action of eribulin in breast cancer.
\end{abstract}

Keywords: eribulin, microtubule-targeting agents, breast cancer

\section{Introduction}

Microtubules are a key component of the cytoskeleton. They are highly dynamic structures that are formed from polymers of $\alpha$ and $\beta$ tubulin heterodimers, aligned into hollow filaments. They play an important role in a variety of cellular processes, including mitosis. Microtubule-targeting agents (MTAs) have an established role in the treatment of various hematopoietic and solid tumors, including breast cancer. MTAs are classified into either microtubule-stabilizing agents (eg, the taxanes paclitaxel and docetaxel) or microtubule-destabilizing agents (eg, the vinca alkaloids vincristine and vinblastine, and the halichondrin analog eribulin). Both microtubule stabilizers and microtubule destabilizers suppress spindle dynamics during mitosis, which leads to mitotic catastrophe and cell death. ${ }^{1}$ Eribulin (HALAVEN) was licensed for the treatment of locally advanced or metastatic breast cancer following the pivotal Eisai Metastatic Breast Cancer Study Assessing Physician's Choice Versus E7389 (EMBRACE) study, an international randomized Phase III clinical trial of eribulin vs treatment of physician's choice in 762 patients with locally recurrent or metastatic breast cancer previously treated with at least two chemotherapy regimens, including an anthracycline and a taxane. ${ }^{2}$ Here, we review the clinical data supporting the use of eribulin for the treatment of metastatic breast cancer and emerging new data around its mode of action.

\section{Pharmacology}

The macrocyclic polyether halichondrin B was isolated from the sea sponge Halichondria okadai in 1986. This compound was found to have promising activity in both in vitro and in vivo tumor assays; however, further drug development was 
limited by the low yields available from natural sources. Following extensive testing of hundreds of simplified synthetic analogs designed around the active C1-C38 macrocyclic lactone moiety, E7389 (eribulin) was selected for clinical development. ${ }^{3}$

\section{Mechanism of action}

Eribulin binds to $\beta$ tubulin at the microtubule plus end, where the $\beta$ tubulin subunit is exposed, to sterically inhibit the polymerization of further tubulin heterodimers. Eribulin thus limits microtubule growth but has very little effect on microtubule shortening. ${ }^{4,5}$ Microtubules are essential for the correct alignment and separation of sister chromatids during the metaphase-anaphase stages of mitosis. The inhibition of microtubule growth by eribulin stalls spindle activity during mitosis, which signals mitotic catastrophe through mitotic checkpoints, and leads to cell death. ${ }^{6,7}$ In contrast to many other MTAs, eribulin exposure is associated with irreversible mitotic blockade, despite drug washout. This property may be relevant clinically, where treatment schedules are typically associated with transient drug exposure. ${ }^{8}$ Interestingly, the efficacy of eribulin correlates inversely with the expression of isoform III of the $\beta$ tubulin subunit. ${ }^{9}$ This isoform is highly expressed in neurons and may partly account for the relatively low neuropathy reported by patients treated with eribulin.

Consistent with the role of microtubules in broader cellular functions, exposure to MTAs is associated with offtarget nonmitotic effects, which are likely to contribute to their clinical efficacy. A recent in vitro study demonstrated reduced intracellular trafficking of DNA repair proteins from the cytoplasm to the nucleus in the presence of noncytotoxic drug concentrations of paclitaxel and vincristine, ${ }^{10}$ supporting the use of MTAs in combination with DNA-damaging agents, including radiotherapy. A similar influence on intracellular trafficking may be predicted with eribulin, although a study exploring the pathogenesis of MTA-induced peripheral neuropathy reported differences between MTA agents in axonal transport along neuronal microtubules; the microtubulestabilizing agents paclitaxel and ixabepilone inhibited anterograde but not retrograde axonal transport, while the microtubule-destabilizing agents eribulin and vincristine had effects on axonal transport only at significantly higher drug concentrations. ${ }^{11}$ Another in vitro study demonstrated that eribulin interfered with the interaction between microtubule plus ends and microtubule tip-associated proteins, which are required for chemotaxis, such as the colonic and hepatic tumor overexpressed gene protein (ch-TOG), leading to decreased breast cancer cell migration. ${ }^{12}$
Epithelial-mesenchymal transition (EMT) is a process crucial to tumor invasion and metastasis and also contributes to chemotherapy resistance. Treatment of triple-negative breast cancer (TNBC) cells with eribulin reduced cell expression of mesenchymal markers and increased the expression of epithelial markers, both in vitro and in vivo. This was associated with decreased breast cancer cell migration and invasion and reduced metastasis formation in vivo. ${ }^{13}$ Furthermore, exposure of TNBC cells to 5-fluorouracil (5-FU) caused a shift from an epithelial to a mesenchymal phenotype and induced resistance to 5-FU. Eribulin reversed 5-FU-induced EMT transition and sensitized TNBC cells to 5-FU.14

Other preclinical studies have confirmed that eribulin treatment is associated with decreased EMT-related gene expression and also decreased angiogenesis-related gene expression, including vascular endothelial growth factor (VEGF) and VEGF receptors; ${ }^{15}$ the antiangiogenic response to eribulin altered the tumor vasculature morphology, improved the tumor perfusion, and enhanced the activity of subsequently administered chemotherapy. A recent interesting clinical study compared differences in breast cancer oxygenation between treatment with eribulin and bevacizumab; ${ }^{16}$ this small study of 29 patients reported that bevacizumab treatment was associated with increased tumor hypoxia, while eribulin treatment was associated with improved tumor oxygenation, despite similar inhibition of circulating VEGF.

To date, resistance mechanisms to eribulin have been relatively understudied. However, it was recently reported that breast cancer cell line expression of the ATP-binding cassette (ABC) efflux pumps, specifically ABCB1 (also known as P-glycoprotein/MDR1) and ABCC11, which confer cross-resistance to various chemotherapies, was also associated with eribulin resistance in vitro. ${ }^{17}$

\section{Pharmacokinetics}

Eribulin forms a clear colorless aqueous solution for injection. In Europe, the recommended dose schedule is $1.23 \mathrm{mg} / \mathrm{m}^{2}$, days 1 and 8 of a 21-day cycle, which refers to the base of the active substance (eribulin). In the USA, the recommended dose is $1.4 \mathrm{mg} / \mathrm{m}^{2}$, which refers to the salt (eribulin mesylate). After intravenous infusion, eribulin has a rapid distribution, followed by triexponential elimination, with a prolonged terminal half-life of 40 hours but no evidence of dose accumulation. ${ }^{18}$ Cytochrome $\mathrm{P} 4503 \mathrm{~A} 4$ has a very minor role in the metabolism of eribulin, and it is predominately eliminated unchanged by biliary excretion. Dose reductions are therefore required in the presence of hepatic impairment ${ }^{19}$ 
and can be guided by the Child-Pugh score. Less than $10 \%$ of eribulin is eliminated by renal excretion; however, decreased clearance and increased exposure have been reported in moderate and severe renal impairment, and dose reduction is suggested if the creatinine clearance is $<50 \mathrm{~mL} / \mathrm{min}^{20}$ Eribulin causes embryo-fetal toxicity and teratogenicity in pregnant rats, and with no clinical studies of its safety in pregnant women, its use is not recommended.

\section{Eribulin in clinical practice Eribulin in advanced breast cancer}

Eribulin is approved for the treatment of locally advanced or metastatic breast cancer in patients who have progressed following prior chemotherapy for advanced disease. The licensing is a little different in Europe than in the USA, stipulating one and two prior chemotherapy regimens for advanced disease, respectively. In either case, previous treatment should include an anthracycline and a taxane in either the adjuvant or metastatic setting. Approval was based on the results of two large, randomized Phase III clinical trials EMBRACE$^{2}$ and the 301 Study (Table 1). ${ }^{21}$

Advanced breast cancer response to eribulin was initially studied in two single-arm Phase II studies. In the $201 \mathrm{Study},{ }^{22}$ patients were initially treated with eribulin on days 1,8 , and 15 of a 28-day cycle. Due to unacceptable hematological toxicity, requiring dose delays and dose modifications, the regimen was adjusted to the now standard schedule of eribulin on days 1 and 8 of a 21-day cycle. The subsequent 211 Study assessed efficacy of this modified schedule in 291 breast cancer patients with heavily pretreated advanced disease. ${ }^{23}$ The objective response rate (ORR; complete + partial response) reported by independent review was $9.3 \%$, the median progression-free survival (PFS) was 2.6 months (range: 0.03-13.1 months), and the median overall survival (OS) was 10.4 months (range: 0.6-19.9 months).
The subsequent EMBRACE study was an international open-label Phase III trial of eribulin compared to treatment of physician's choice in breast cancer patients pretreated with two to five prior chemotherapy regimens including an anthracycline and a taxane. ${ }^{2} \mathrm{~A}$ total of 762 patients were randomized (2:1) to eribulin or treatment of physician's choice (vinorelbine $25 \%$, gemcitabine $19 \%$, capecitabine $18 \%$, and others $38 \%$ ). The study reported a 2.5 -month improvement in OS with eribulin (median OS 13.1 vs 10.6 months, hazard ratio $[\mathrm{HR}]=0.81,95 \%$ confidence interval $[\mathrm{CI}]$ : 0.66-0.99; $P=0.041)$. A small increase in PFS was reported for the eribulin group on independent review, but the HR was not statistically significant (median PFS 3.7 vs 2.2 months, $\mathrm{HR}=0.87,95 \% \mathrm{CI}: 0.71-1.05 ; P=0.137)$. The ORR by independent review was $12 \%$ vs $5 \%(P=0.002)$.

The 301 Study was an international open-label Phase III trial of eribulin compared to capecitabine in 1102 women with metastatic breast cancer who had received up to two lines of prior chemotherapy for advanced disease, ${ }^{21} 20 \%, 52 \%$, and $27 \%$ of patients received study treatment as first-, second-, and third-line therapies, respectively. The study reported no significant difference between treatment arms for OS, PFS, or ORR. The median OS was 15.9 and 14.5 months for the eribulin and capecitabine groups, respectively $(\mathrm{HR}=0.88$, 95\% CI: $0.77-1.00 ; P=0.056)$. The median PFS was 4.1 vs 4.2 months $(\mathrm{HR}=1.08,95 \% \mathrm{CI}: 0.93-1.25 ; P=0.30)$, and the ORR was 11.0 vs $11.5 \%(P=0.85)$.

A pooled analysis of these two Phase III trials reported an overall OS benefit of 2.4 months with eribulin compared to that with control therapy $(\mathrm{HR}=0.85,95 \% \mathrm{CI}$ : $0.77-0.95$; $P=0.003)$ and an overall PFS benefit of 0.6 months $(H R=0.90$, 95\% CI: 0.81-0.997; $P=0.046) .{ }^{24}$ All analyzed patient subgroups favored treatment with eribulin compared to control, with particular OS benefit observed in patients with Her2negative disease $(\mathrm{HR}=0.82,95 \% \mathrm{CI}: 0.72-0.93 ; P=0.002)$,

Table I Clinical trials leading to the licensing of eribulin for locally advanced and metastatic breast cancer

\begin{tabular}{|c|c|c|c|c|c|c|}
\hline Study & Study design & Eligibility criteria & $\begin{array}{l}\text { Number } \\
\text { of patients }\end{array}$ & ORR (\%) & Median PFS & Median OS \\
\hline $\begin{array}{l}\text { Cortes } \\
\text { et } \mathrm{a}^{23}\end{array}$ & Single-arm Phase II & $\begin{array}{l}\text { Prior anthracycline, } \\
\text { taxane and capecitabine }\end{array}$ & 291 & 9.3 & $\begin{array}{l}2.6 \text { months } \\
(0.03-13.1 \text { months })\end{array}$ & $\begin{array}{l}10.4 \text { months } \\
(0.6-19.9 \text { months })\end{array}$ \\
\hline $\begin{array}{l}\text { Cortes } \\
\text { et } \mathrm{al}^{2}\end{array}$ & $\begin{array}{l}\text { Open-label randomized } \\
\text { Phase III, eribulin } \\
\text { vs treatment of } \\
\text { physicians choice }\end{array}$ & $\begin{array}{l}\text { Two to five previous } \\
\text { chemotherapy regimens } \\
\text { including an anthracycline } \\
\text { and a taxane }\end{array}$ & 762 & 12 vs 5 & $\begin{array}{l}3.7 \text { vs } 2.2 \text { months, } \mathrm{HR}=0.87 \\
(95 \% \mathrm{Cl}: 0.7 \mathrm{I}-\mathrm{I} .05), P=0.137\end{array}$ & $\begin{array}{l}\text { I } 3 . \mid \text { vs } 10.6 \text { months, } \mathrm{HR}=0.8 \mathrm{I} \\
(95 \% \mathrm{Cl}: 0.66-0.99), P=0.04 \mid\end{array}$ \\
\hline $\begin{array}{l}\text { Kaufman } \\
\text { et } \mathrm{al}^{21}\end{array}$ & $\begin{array}{l}\text { Open-label randomized } \\
\text { Phase III, eribulin } \\
\text { vs capecitabine }\end{array}$ & $\begin{array}{l}\text { Up to two prior } \\
\text { chemotherapy regimens } \\
\text { for advanced disease }\end{array}$ & 1,102 & II.0 vs II.5 & $\begin{array}{l}4.1 \text { vs } 4.2 \text { months, } H R=1.08 \\
\text { (95\% Cl: } 0.93-1.25), P=0.30\end{array}$ & $\begin{array}{l}\text { I } 5.9 \text { vs } \mid 4.5 \text { months, } H R=0.88 \\
(95 \% \mathrm{Cl}: 0.77-\mathrm{I} .00), P=0.056\end{array}$ \\
\hline
\end{tabular}

Abbreviations: $\mathrm{Cl}$, confidence interval; ORR, objective response rate; OS, overall survival; PFS, progression-free survival. 
Table 2 Postlicensing studies of eribulin in patients with advanced breast cancer

\begin{tabular}{|c|c|c|c|c|c|c|c|}
\hline Study & Study design & Study treatment & Eligibility criteria & $\begin{array}{l}\text { Number } \\
\text { of patients }\end{array}$ & ORR (\%) & $\begin{array}{l}\text { Median PFS } \\
\text { (months) }\end{array}$ & $\begin{array}{l}\text { Median OS } \\
\text { (months) }\end{array}$ \\
\hline $\begin{array}{l}\text { Mclntyre } \\
\text { et } \mathrm{al}^{28}\end{array}$ & Single-arm Phase II & Eribulin & First-line therapy, Her2-negative & 56 & 28.6 & 6.8 & NR \\
\hline $\begin{array}{l}\text { Wilks } \\
\text { et } \text { al }^{29}\end{array}$ & Single-arm Phase II & Eribulin + trastuzumab & First-line therapy, Her2-positive & 52 & 7I & II.6 & NR \\
\hline $\begin{array}{l}\text { Yardley } \\
\text { et } \mathrm{al}^{30}\end{array}$ & Randomized Phase II & Eribulin \pm ramucirumab & $\begin{array}{l}\text { Two to four previous chemotherapy } \\
\text { regimens including an anthracycline } \\
\text { and a taxane }\end{array}$ & $|4|$ & 21 vs 28 & 4.4 vs 4.1 & I3.5 vs II.5 \\
\hline
\end{tabular}

Abbreviations: NR, not reported; ORR, objective response rate; OS, overall survival; PFS, progression-free survival.

TNBC $(\mathrm{HR}=0.74,95 \%$ CI: $0.60-0.92 ; P=0.006)$, and patients with $>2$ organs involved with disease (HR $=0.77,95 \%$ CI: $0.66-0.89 ; P<0.001)$.

It is interesting to speculate on why eribulin may improve OS with little gain in PFS. As previously discussed, eribulin has various antitumor effects, including reversal of EMT, vascular remodeling, and associated improvement in tumor hypoxia. These effects may alter the biology of the underlying disease and enhance tumor response to subsequent chemotherapy. ${ }^{15}$ Subsequent clinical studies have sought to develop the role of eribulin for the treatment of breast cancer, either in specific patient subgroups, earlier in the patient pathway, or in combination with other anticancer therapies (Table 2).

Studies have largely reported response to eribulin in female breast cancer patients; however, a small retrospective study suggests efficacy in male breast cancer patients too. ${ }^{25}$ Older patients are often excluded from clinical trials. A pooled analysis of 827 patients treated in either the EMBRACE trial or the preceding Phase II studies reported outcomes according to age. ${ }^{26} \mathrm{~A}$ total of $10 \%$ of patients included in these studies were aged $\geq 70$ years. No significant differences were observed in ORR, PFS, or OS by age. Toxicity was similar across all age groups, although the incidence of grade 3/4 fatigue and peripheral neuropathy was highest in patients aged $\geq 70$ years. A current study is specifically addressing the question of toxicity and response to eribulin in older patients ( $>70$ years) with advanced breast cancer (NCT02404506). Patients with brain metastases are also often excluded from clinical trials. There have been several case reports describing response to eribulin in breast cancer patients with brain metastases, ${ }^{27}$ and a small prospective study to assess eribulin response in this group of patients is currently open to recruitment (NCT02581839).

A single-arm Phase II study of eribulin as first-line therapy for 56 patients with locally advanced or metastatic Her2-negative breast cancer reported an ORR of $28.6 \%$ and a median PFS of 6.8 months (95\% CI: 4.4-7.6 months). ${ }^{28}$ A Phase III trial of eribulin compared to weekly paclitaxel as first- or second-line therapy for patients with locally recurrent or metastatic Her2-negative breast cancer is currently open to recruitment (NCT02037529).

A single-arm Phase II study of eribulin + trastuzumab as first-line therapy for 52 patients with advanced Her2positive breast cancer reported promising activity with an ORR of $71 \%$ and a median PFS of 11.6 months $(95 \%$ CI: $11.6-13.9$ months). ${ }^{29}$ With current standard of care for first-line Her2-positive advanced breast cancer patients now including pertuzumab, the results of an ongoing Phase II study of eribulin in combination with trastuzumab + pertuzumab (NCT01912963) will provide an indication of its utility earlier in the treatment pathway for these patients.

Eribulin clearly has supportive data for its use as a monotherapy in metastatic breast cancer, particularly in Her2-negative breast cancer and TNBC, and future studies will inform clinicians on its efficacy and safety in combination regimes.

The well-documented effects of eribulin on the tumor vasculature provided a rationale for studying the combination of eribulin with antiangiogenic therapy. A recently reported randomized Phase II study of 141 patients with metastatic breast cancer treated with eribulin \pm ramucirumab, a recombinant human monoclonal antibody to VEGF receptor-2, reported no significant difference either in PFS, the primary endpoint (median PFS 4.4 vs 4.1 months, HR $=0.83$, 95\% CI: $0.56-1.23 ; P=0.35$ ), or in the secondary endpoints of OS and ORR. ${ }^{30}$ A study of eribulin in combination with bevacizumab for Her2-negative metastatic breast cancer is currently recruiting (NCT02175446).

A randomized Phase II study of eribulin + gemcitabine compared to paclitaxel + gemcitabine as first-line therapy for patients with Her2-negative metastatic breast cancer is ongoing (NCT02263495). A study of eribulin in combination with the humanized antibody to programmed cell death-1 (PD-1) 
Table 3 Clinical trials of neoadjuvant eribulin in early breast cancer

\begin{tabular}{|c|c|c|c|c|c|}
\hline Study & Study design & Study treatment & Eligibility criteria & $\begin{array}{l}\text { Number } \\
\text { of patients }\end{array}$ & PCR (\%) \\
\hline $\begin{array}{l}\text { Abraham } \\
\text { et } \mathrm{a}^{3 !}\end{array}$ & Randomized (2:I) Phase II & $\begin{array}{l}\text { Eribulin vs weekly paclitaxel, then } \\
\text { doxorubicin }+ \text { cyclophosphamide }\end{array}$ & Her2-negative & 49 & 17 vs 26 \\
\hline $\begin{array}{l}\text { Yardley } \\
\text { et al }{ }^{32}\end{array}$ & Randomized (2:I) Phase II & $\begin{array}{l}\text { Eribulin }+ \text { cyclophosphamide vs } \\
\text { docetaxel + cyclophosphamide }\end{array}$ & Her2-negative & 66 & I4 vs II \\
\hline $\begin{array}{l}\text { Kaklamani } \\
\text { et } \mathrm{al}^{33}\end{array}$ & Single-arm Phase II & Eribulin + carboplatin & TNBC & 30 & 43 \\
\hline $\begin{array}{l}\text { Schwartzberg } \\
\text { et a }{ }^{34}\end{array}$ & Phase I/II & Eribulin + carboplatin + trastuzumab & Her2-positive & 12 & 17 \\
\hline
\end{tabular}

Abbreviations: $\mathrm{PCR}$, pathological complete response; TNBC, triple-negative breast cancer.

receptor, pembrolizumab, for patients with metastatic TNBC is currently open to recruitment (NCT02513472). Other interesting combination studies currently open to recruitment in metastatic TNBC include eribulin + the mammalian target of rapamycin (mTOR) inhibitor everolimus (NCT02120469) and eribulin + PQR309, a pan phosphoinositide-3-kinase (PI3K) and mTOR inhibitor (NCT02723877).

\section{Eribulin in early breast cancer}

The ORR reported by studies of eribulin in pretreated patients with metastatic breast cancer is limited; however, the reduced peripheral neuropathy associated with eribulin treatment compared to other MTAs means that it is appealing as a potential option in the adjuvant and neoadjuvant settings (Table 3). A randomized (2:1) Phase II study of eribulin or weekly paclitaxel followed by doxorubicin and cyclophosphamide in 49 women with locally advanced nonmetastatic Her2-negative breast cancer reported pathological complete response (pCR) in 5/30 (17\%) and 5/19 (26\%) patients, respectively, ${ }^{31}$ with similar rates of breast-conserving surgery following either regime ( $28 \%$ vs $33 \%$ ); reported levels of neurotoxicity were minimal and similar in both arms. Preliminary reports from a randomized (2:1) Phase II study of eribulin + cyclophosphamide vs docetaxel + cyclophosphamide in 66 patients with locally advanced Her2-negative breast cancer reported pCR in 5/37 (14\%) and 2/18 (11\%) patients, respectively; ${ }^{32}$ the incidence of peripheral neuropathy with docetaxel was worse than with eribulin $(45 \%$ vs $30 \%$ of patients). A Phase II study of neoadjuvant eribulin + carboplatin in 30 women with TNBC reported pCR in 13/30 (43\%) patients. ${ }^{33} \mathrm{~A}$ Phase I/II study of neoadjuvant eribulin + carboplatin + trastuzumab for early Her2-positive breast cancer reported pCR in 2/12 (17\%) patients but reported unacceptable hematological toxicity with grade $3 / 4$ neutropenia in $9 / 12$ patients, anemia requiring blood transfusion in $8 / 12$ patients, and thrombocytopenia requiring platelet transfusion in $2 / 12$ patients. ${ }^{34}$
It is unlikely with current evidence that eribulin in the neoadjuvant setting will replace current standard regimes. However, it may have a role as an adjuvant therapy in patients who do not achieve pCR with standard regimes, and an ongoing Phase II trial is evaluating the use of eribulin in these patients (NCT01401959). In addition, a recent Phase II study assessed eribulin + capecitabine as adjuvant therapy in postmenopausal women with early-stage, Her2-negative, estrogen receptor (ER)-positive breast cancer, ${ }^{35}$ this combination was considered feasible and suitable for further study in a larger randomized trial.

\section{Safety and tolerability}

Eribulin has an acceptable side effect profile (Table 4). The most common adverse events reported in the EMBRACE ${ }^{2}$

Table 4 Pooled incidence of common adverse events reported by patients treated with eribulin $(n=I, 047)$ in the two randomized Phase III trials of eribulin for advanced breast cancer (EMBRACE ${ }^{2}$ and 30 I Study ${ }^{21}$ )

\begin{tabular}{|c|c|c|c|c|c|c|}
\hline \multirow{2}{*}{$\begin{array}{l}\text { Adverse } \\
\text { event }\end{array}$} & \multicolumn{2}{|l|}{ All grades } & \multicolumn{2}{|l|}{ Grade 3} & \multicolumn{2}{|l|}{ Grade 4} \\
\hline & $\begin{array}{l}\text { Number } \\
\text { of patients }\end{array}$ & $\%$ & $\begin{array}{l}\text { Number } \\
\text { of patients }\end{array}$ & $\%$ & $\begin{array}{l}\text { Number } \\
\text { of patients }\end{array}$ & $\%$ \\
\hline Neutropenia & 555 & 53 & 240 & 23 & 236 & 23 \\
\hline Leukopenia & 287 & 27 & 132 & 13 & 20 & 2 \\
\hline Anemia & 198 & 19 & 20 & 2 & 1 & $<1$ \\
\hline Fatigue/asthenia & 444 & 42 & 74 & 7 & 4 & $<1$ \\
\hline Alopecia & 412 & 39 & & & & \\
\hline $\begin{array}{l}\text { Peripheral } \\
\text { neuropathy }\end{array}$ & 323 & 31 & 74 & 7 & 5 & $<1$ \\
\hline Nausea & 295 & 28 & 7 & I & 0 & 0 \\
\hline Diarrhea & 170 & 16 & 6 & I & 0 & 0 \\
\hline Pyrexia & 175 & 17 & 3 & $<1$ & 0 & 0 \\
\hline Headache & 166 & 16 & 6 & I & 0 & 0 \\
\hline Anorexia & 166 & 16 & 5 & $<1$ & 0 & 0 \\
\hline Vomiting & 156 & 15 & 5 & $<1$ & 2 & $<1$ \\
\hline Back pain & 135 & 13 & II & I & I & $<1$ \\
\hline Dyspnea & 135 & 13 & 28 & 3 & 2 & $<1$ \\
\hline Bone pain & 110 & 11 & 19 & 2 & I & $<1$ \\
\hline
\end{tabular}


and 301 Study $^{21}$ were hematological toxicities, including grade $3 / 4$ neutropenia in $45 \%$ of patients; despite this, the reported incidence of febrile neutropenia across both studies was low (3\%). Other common adverse events included alopecia, nausea, and fatigue. Peripheral neuropathy (all grades) was reported in $31 \%$ of patients, with grade $3 / 4$ peripheral neuropathy in $8 \%$ of cases.

A health-related quality of life analysis of patients treated within the 301 Study reported similar treatment effects on patient functioning irrespective of treatment arm. As might be expected from their side effect profiles, patients treated with capecitabine reported worse gastrointestinal symptoms (diarrhea, nausea, and vomiting), while patients treated with eribulin reported worse systemic side effects, including hair loss, dry eyes, altered taste, and headaches. ${ }^{36}$

Three recent retrospective studies have reported multiinstitutional experience with eribulin in clinical practice. ${ }^{37-39}$ Of these three studies, 504 patients with advanced breast cancer received eribulin. Treatment responses and adverse events were consistent with outcomes reported from the prospective randomized Phase III trials. Toxicity data may have been incompletely reported by these retrospective studies, but the pooled incidence of the most common toxicities (all grades) was fatigue (59\%), neutropenia (35\%), and peripheral neuropathy (34\%); grade 3/4 neuropathy was reported in $16 / 504$ patients $(3 \%)$. These studies underline the tolerability of eribulin therapy by patients and its comparable side effect profile with other chemotherapeutic agents used in the management of metastatic breast cancer.

\section{Conclusion}

Eribulin is a novel MTA, which is now well established as a treatment option for patients with advanced breast cancer who have previously received chemotherapy with an anthracycline and a taxane. Preclinical studies demonstrate that eribulin has wider antitumor effects beyond that of a simple antimitotic agent, including tumor vascular remodeling and reversal of EMT. The clinically significant improvements in OS, despite modest differences in PFS reported by the large randomized Phase III clinical trials of eribulin in advanced breast cancer patients, suggest that these off-target effects play an important contribution to its therapeutic activity. Ongoing and future studies will further define the role for eribulin in the treatment of both early and advanced breast cancer, as a monotherapy and in combination with other anticancer agents.

\section{Disclosure}

The authors report no conflicts of interest in this work.

\section{References}

1. Mukhtar E, Adhami VM, Mukhtar H. Targeting microtubules by natural agents for cancer therapy. Mol Cancer Ther. 2014;13(2):275-284.

2. Cortes J, O'Shaughnessy J, Loesch D, et al. Eribulin monotherapy versus treatment of physician's choice in patients with metastatic breast cancer (EMBRACE): a phase 3 open-label randomised study. Lancet. 2011;377(9769):914-923.

3. Towle MJ, Salvato KA, Budrow J, et al. In vitro and in vivo anticancer activities of synthetic macrocyclic ketone analogues of halichondrin B. Cancer Res. 2001;61(3):1013-1021.

4. Doodhi H, Prota AE, Rodríguez-García R, et al. Termination of protofilament elongation by eribulin induces lattice defects that promote microtubule catastrophes. Curr Biol. 2016;26(13):1713-1721.

5. Smith JA, Wilson L, Azarenko O, et al. Eribulin binds at microtubule ends to a single site on tubulin to suppress dynamic instability. Biochemistry. 2010;49(6):1331-1337.

6. Okouneva T, Azarenko O, Wilson L, Littlefield BA, Jordan MA. Inhibition of centromere dynamics by eribulin (E7389) during mitotic metaphase. Mol Cancer Ther. 2008;7(7):2003-2011.

7. Mc Gee MM. Targeting the mitotic catastrophe signaling pathway in cancer. Mediators Inflamm. 2015;2015:146282.

8. Towle MJ, Salvato KA, Wels BF, et al. Eribulin induces irreversible mitotic blockade: implications of cell-based pharmacodynamics for in vivo efficacy under intermittent dosing conditions. Cancer Res. 2011;71(2): 496-505.

9. Wilson L, Lopus M, Miller HP, et al. Effects of eribulin on microtubule binding and dynamic instability are strengthened in the absence of the $\beta$ III tubulin isotype. Biochemistry. 2015;54(42):6482-6489.

10. Poruchynsky MS, Komlodi-Pasztor E, Trostel S, et al. Microtubuletargeting agents augment the toxicity of DNA-damaging agents by disrupting intracellular trafficking of DNA repair proteins. Proc Natl Acad Sci U S A. 2015;112(5):1571-1576.

11. Smith JA, Slusher BS, Wozniak KM, et al. Structural basis for induction of peripheral neuropathy by microtubule-targeting cancer drugs. Cancer Res. 2016;76(17):5115-5123.

12. Chanez B, Gonçalves A, Badache A, Verdier-Pinard P. Eribulin targets a ch-TOG-dependent directed migration of cancer cells. Oncotarget. 2015;6(39):41667-41678.

13. Yoshida T, Ozawa Y, Kimura T, et al. Eribulin mesilate suppresses experimental metastasis of breast cancer cells by reversing phenotype from epithelial-mesenchymal transition (EMT) to mesenchymal-epithelial transition (MET) states. Br J Cancer. 2014;110(6):1497-1505.

14. Terashima M, Sakai K, Togashi Y, et al. Synergistic antitumor effects of S-1 with eribulin in vitro and in vivo for triple-negative breast cancer cell lines. Springerplus. 2014;3:417.

15. Funahashi Y, Okamoto K, Adachi Y, et al. Eribulin mesylate reduces tumor microenvironment abnormality by vascular remodeling in preclinical human breast cancer models. Cancer Sci. 2014;105(10): 1334-1342.

16. Ueda S, Saeki T, Takeuchi H, et al. In vivo imaging of eribulin-induced reoxygenation in advanced breast cancer patients: a comparison to bevacizumab. Br J Cancer. 2016;114(11):1212-1218.

17. Oba $\mathrm{T}$, Izumi $\mathrm{H}$, Ito $\mathrm{KI}$. $\mathrm{ABCB} 1$ and $\mathrm{ABCC} 11$ confer resistance to eribulin in breast cancer cell lines. Oncotarget. 2016;7(43):70011-70027.

18. Morgan RJ, Synold TW, Longmate JA, et al. Pharmacodynamics (PD) and pharmacokinetics (PK) of E7389 (eribulin, halichondrin B analog) during a phase I trial in patients with advanced solid tumors: a California Cancer Consortium trial. Cancer Chemother Pharmacol. 2015;76(5):897-907.

19. Devriese LA, Witteveen PO, Marchetti S, et al. Pharmacokinetics of eribulin mesylate in patients with solid tumors and hepatic impairment. Cancer Chemother Pharmacol. 2012;70(6):823-832.

20. Tan AR, Sarantopoulos J, Lee L, et al. Pharmacokinetics of eribulin mesylate in cancer patients with normal and impaired renal function. Cancer Chemother Pharmacol. 2015;76(5):1051-1061.

21. Kaufman PA, Awada A, Twelves C, et al. Phase III open-label randomized study of eribulin mesylate versus capecitabine in patients with locally advanced or metastatic breast cancer previously treated with an anthracycline and a taxane. J Clin Oncol. 2015;33(6):594-601. 
22. Vahdat LT, Pruitt B, Fabian CJ, et al. Phase II study of eribulin mesylate, a halichondrin $\mathrm{B}$ analog, in patients with metastatic breast cancer previously treated with an anthracycline and a taxane. J Clin Oncol. 2009;27(18):2954-2961.

23. Cortes J, Vahdat L, Blum JL, et al. Phase II study of the halichondrin B analog eribulin mesylate in patients with locally advanced or metastatic breast cancer previously treated with an anthracycline, a taxane, and capecitabine. J Clin Oncol. 2010;28(25):3922-3928.

24. Twelves C, Cortes J, Vahdat L, et al. Efficacy of eribulin in women with metastatic breast cancer: a pooled analysis of two phase 3 studies. Breast Cancer Res Treat. 2014;148(3):553-561.

25. Giotta F, Acito L, Candeloro G, et al. Eribulin in male patients with breast cancer: the first report of clinical outcomes. Oncologist. Epub 2016 Oct 14.

26. Muss H, Cortes J, Vahdat LT, et al. Eribulin monotherapy in patients aged 70 years and older with metastatic breast cancer. Oncologist. 2014; 19(4):318-327.

27. Byun KD, Ahn SG, Baik HJ, et al. Eribulin mesylate combined with local treatment for brain metastasis from breast cancer: two case reports. J Breast Cancer. 2016;19(2):214-217.

28. McIntyre K, O'Shaughnessy J, Schwartzberg L, et al. Phase 2 study of eribulin mesylate as first-line therapy for locally recurrent or metastatic human epidermal growth factor receptor 2-negative breast cancer. Breast Cancer Res Treat. 2014;146(2):321-328.

29. Wilks S, Puhalla S, O’Shaughnessy J, et al. Phase 2, multicenter, singlearm study of eribulin mesylate with trastuzumab as first-line therapy for locally recurrent or metastatic HER2-positive breast cancer. Clin Breast Cancer. 2014;14(6):405-412.

30. Yardley DA, Reeves J, Dees EC, et al. Ramucirumab with eribulin versus eribulin in locally recurrent or metastatic breast cancer previously treated with anthracycline and taxane therapy: a multicenter, randomized, phase II study. Clin Breast Cancer. 2016;16(6):471-479.e1.

31. Abraham J, Robidoux A, Tan AR, et al. Phase II randomized clinical trial evaluating neoadjuvant chemotherapy regimens with weekly paclitaxel or eribulin followed by doxorubicin and cyclophosphamide in women with locally advanced HER2-negative breast cancer: NSABP Foundation Study FB-9. Breast Cancer Res Treat. 2015;152(2):399-405.
32. Yardley D, Dyehouse K, Mani A, et al. Abstract P3-11-08: eribulin/ cyclophosphamide (ErC) versus docetaxel/cyclophosphamide (TC) as neoadjuvant therapy in locally advanced HER2-negative breast cancer: a randomized phase II trial of the Sarah Cannon Research Institute. Cancer Res. 2015;75(9 suppl):P3-11-08.

33. Kaklamani VG, Jeruss JS, Hughes E, et al. Phase II neoadjuvant clinical trial of carboplatin and eribulin in women with triple negative earlystage breast cancer (NCT01372579). Breast Cancer Res Treat. 2015; 151(3):629-638.

34. Schwartzberg LS, Tauer KW, Hermann RC, Nikolinakos PG, Houts AC. Phase I/II study of neoadjuvant eribulin mesylate, carboplatin, and trastuzumab (ECH) for operable HER2 positive (HER2+) breast cancer. J Clin Oncol. 2014;32(15 suppl):abstr 604.

35. Smith JW, Vukelja S, Hoffman AD, et al. Phase II, multicenter, single-arm, feasibility study of eribulin combined with capecitabine for adjuvant treatment in estrogen receptor-positive, early-stage breast cancer. Clin Breast Cancer. 2016;16(1):31-37.

36. Cortes J, Hudgens S, Twelves C, et al. Health-related quality of life in patients with locally advanced or metastatic breast cancer treated with eribulin mesylate or capecitabine in an open-label randomized phase 3 trial. Breast Cancer Res Treat. 2015;154(3):509-520.

37. Garrone O, Montemurro F, Saggia C, et al. Eribulin in pretreated metastatic breast cancer patients: results of the TROTTER trial-a multicenter retrospective study of eribulin in real life. Springerplus. 2016;5:59.

38. Dell'Ova M, De Maio E, Guiu S, et al. Tumour biology, metastatic sites and taxanes sensitivity as determinants of eribulin mesylate efficacy in breast cancer: results from the ERIBEX retrospective, international, multicenter study. BMC Cancer. 2015;15:659.

39. Gamucci T, Michelotti A, Pizzuti L, et al. Eribulin mesylate in pretreated breast cancer patients: a multicenter retrospective observational study. J Cancer. 2014;5(5):320-327.
OncoTargets and Therapy

\section{Publish your work in this journal}

OncoTargets and Therapy is an international, peer-reviewed, open access journal focusing on the pathological basis of all cancers, potential targets for therapy and treatment protocols employed to improve the management of cancer patients. The journal also focuses on the impact of management programs and new therapeutic agents and protocols on

\section{Dovepress}

patient perspectives such as quality of life, adherence and satisfaction. The manuscript management system is completely online and includes a very quick and fair peer-review system, which is all easy to use. Visit http://www.dovepress.com/testimonials.php to read real quotes from published authors. 